\title{
Ambient Air Waste Sorting Facilities Could Be a Source of Antibiotic Resistant Bacteria
}

\author{
Ana Calheiros ${ }^{1}$, Joana Santos ${ }^{1,2}$, Carla Ramos ${ }^{1}$, Marta Vasconcelos ${ }^{2,3}$, and Paulo Fernandes ${ }^{1,2 *}$ \\ ${ }^{1}$ Escola Superior de Tecnologia e Gestão, Instituto Politécnico de Viana do Castelo, Rua Escola Industrial e Comercial de Nun'Álvares, \\ 4900-347, Viana do Castelo, Portugal \\ ${ }^{2}$ CISAS, Escola Superior de Tecnologia e Gestão, Instituto Politécnico de Viana do Castelo, Rua Escola Industrial e Comercial de Nun'Álvares, \\ 4900-347, Viana do Castelo, Portugal \\ ${ }^{3}$ Instituto Politécnico de Coimbra, ESTESC-Coimbra Health School, Saúde Ambiental, Coimbra, Portugal
}

Received: February 15, 2021 / Revised: April 7, 2021 / Accepted: April 8, 2021

The antimicrobial resistance of Staphylococcus spp. and Gram negative strains present in air samples from waste sorting facilities was assessed. Phenotypic studies have revealed a high percentage of strains of Staphylococcus spp. resistant to methicillin. Genotypically and by RT-PCR, it was found that the mecA gene usually associated with methicillin resistance was present in $8 \%$ of the Staphylococcus strains isolated. About 30\% of the Gram negative strains from the same samples also displayed resistance to meropenem and $79 \%$ of these were resistant to multiple antibiotics from different classes, namely cephalosporins and $\beta$ lactams. The results suggest that in professional activities with high levels of exposure to biological agents, the quantification and identification of the microbial flora in the work environment, with the determination of the presence of potential agents displaying multi-resistances is of relevance to the risk assessment. The personal protection of workers is particularly important relevance in these cases, since many of the strains that exhibit multi-resistance are potential opportunistic agents.

Keywords: Staphylococcus, Enterobacteriaceae, biological risk, antimicrobial resistance

\section{Introduction}

Antimicrobial resistance (AMR) is, nowadays, a significant threat to global health [1,2]. Risk assessment in professional activities where exposure to biological agents can be frequent and intense, has been performed. However, current risk assessment models are inadequate to evaluate the effect of antibiotics and antibiotic resistance genes (ARGs), especially in non-clinical environments [3]. When biological agents are introduced into workplaces as part of the process, for example in a laboratory or in biotechnology, workers usually show high levels of awareness of the biological hazards to

*Corresponding author

Tel.: +351 258819700, Fax: +351258827636

E-mail: paulof@estg.ipvc.pt which they are exposed, knowing and using correct protective measures. However, this level of consciousness does not exist in other workplaces where biological agents are present, not as an integral part of the activities performed, but as contaminants.

The "Expert Forecast on Emerging Biological Risks Related to Occupational Safety and Health" of the European Agency for Safety and Health at Work stated that the introduction of new treatment technologies and manual sorting brought new risks to workers involved in collecting, sorting, recovery, and final disposal of waste [4]. The waste management and recycling sector is thriving and the number of workers is sharply increasing [5], although it has not been subject to many studies on biological risk assessment. Associated with this theme we can observe an increasing trend to find antibiotic resistant bacteria (ARB) in the community. This fact, com- 
bined with the existence of opportunistic strains, usually considered of reduced risk of infection but potentially carriers of multiple resistance genes, are factors of increased risk for workers whose magnitude is, in fact, virtually unknown.

The purpose of this study was the evaluation of antibiotic resistance in a set of microorganisms, namely by characterising the antimicrobial resistance of Staphylococcus spp. and Gram negative strains isolated from air samples from waste sorting facilities.

\section{Methods}

\section{Strains of Staphylococcus spp. isolated from air samples}

Forty-nine strains isolated from a total of 409 air samples collected in glass waste sorting facilities previously identified as Staphylococcus spp. [5], were preserved at $-80^{\circ} \mathrm{C}$ in BHI (Biokar Diagnostic, France) with $15 \%(\mathrm{v} / \mathrm{v})$ glycerol (Merck, Germany) and regenerated in $5 \mathrm{ml}$ of BHI medium at $37^{\circ} \mathrm{C}$ (Sanyo Incubator, Japan) overnight. After inoculation by streak plate of TSA medium (Biokar Diagnostics) on Petri plates $(\varnothing=90 \mathrm{~mm}$ ) and incubation at $37^{\circ} \mathrm{C}$ for $18-24 \mathrm{~h}$, colonies were used for antibiotic susceptibility testing.

\section{Screening and isolation of Gram negative strains resistant to meropenem}

Colony suspensions preserved at $-80^{\circ} \mathrm{C}$ in phosphate buffer saline (PBS) with 15\% (v/v) glycerol, of 133 air samples obtained from the analysis of waste sorting facilities and containing Enterobacteriaceae [5], were thawed overnight at $4^{\circ} \mathrm{C}$. After keeping for $1 \mathrm{~h}$ at $30^{\circ} \mathrm{C}$ (Certomat H, B. Braun Biotech International, Germany), $100 \mu \mathrm{l}$ of each suspension were initially inoculated in $5 \mathrm{ml}$ of BHI medium with $2 \mu \mathrm{g} / \mathrm{ml}$ meropenem (Sigma Aldrich, Germany) and incubated at $37^{\circ} \mathrm{C}$ during $18-24 \mathrm{~h}$. The cultures that showed growth after $24 \mathrm{~h}$ at $37^{\circ} \mathrm{C}$ were inoculated by streak plate on MacConkey agar (Biokar Diagnostics, France) containing $2 \mu \mathrm{g} / \mathrm{ml}$ meropenem and incubated during $18-24 \mathrm{~h}$ at $37^{\circ} \mathrm{C}$. The colonies obtained were then transferred to plates with TSA medium and incubated $18-24 \mathrm{~h}$ at $37^{\circ} \mathrm{C}$ for further studies.

\section{Antimicrobial susceptibility testing by agar diffusion method}

Antimicrobial susceptibility test was performed by the agar disc diffusion method using Mueller-Hinton (MH, Oxoid, England) agar and the methods described by and according to CLSI and EUCAST standards [6-8].

Isolated colonies grown on TSA, plates were resuspended in sterile $0.85 \%(\mathrm{w} / \mathrm{v}) \mathrm{NaCl}$ (VWR, USA). After homogenization in the vortex (Stuart Scientific CO, Great Britain), turbidity (Biolog, USA) was measured and the concentration of the suspension adjusted until its turbidity corresponds to that of a standard 0.5 MacFarland solution. The MH plates were inoculated with the inoculum prepared previously, with a swab in order to completely fill the plate. The antibiotic discs, stored in the freezer at $-20 \pm 5{ }^{\circ} \mathrm{C}$, were removed and placed at room temperature $1 \mathrm{~h}$ before being used. The discs were aseptically placed at least $1.5 \mathrm{~cm}$ apart from each other and from the wall of the Petri dish. The inhibition halos were read after $18 \pm 2 \mathrm{~h}$ of incubation, according to the EUCAST guide [9].

The plates were incubated at $37^{\circ} \mathrm{C}$ overnight. Zones of inhibition on the agar plates were measured and the results were recorded and antimicrobial susceptibility classified according to corresponding internationally accepted breakpoints.

Table 1. Antimicrobial agents used in disc diffusion assays for antimicrobial susceptibility determination.

\begin{tabular}{|c|c|c|}
\hline Class & Antimicrobial agent & $\begin{array}{c}\text { Disc potency } \\
(\mu \mathrm{g})\end{array}$ \\
\hline \multirow[t]{2}{*}{ Glicopeptides } & Vancomycine $^{1}$ & 30 \\
\hline & Teicoplanin ${ }^{2}$ & 30 \\
\hline \multirow[t]{2}{*}{ Fluoroquinolones } & Ciprofloxacin ${ }^{1}$ & 5 \\
\hline & Nalidixic acid ${ }^{2}$ & 30 \\
\hline Macrolídeos & Erythromycin ${ }^{1}$ & 15 \\
\hline \multirow[t]{3}{*}{ Aminoglycosides } & Gentamicin ${ }^{1}$ & 10 \\
\hline & Amikacin $^{1}$ & 30 \\
\hline & Neomicin $^{2}$ & 10 \\
\hline \multirow[t]{2}{*}{ Cefalosporinas } & Cefoxitin ${ }^{2}$ & 30 \\
\hline & Cefalotin $^{2}$ & 30 \\
\hline \multirow[t]{3}{*}{ Penicillins } & Ampicillin ${ }^{1}$ & 10 \\
\hline & Penicillin $^{2}$ & 10 \\
\hline & Amoxicillin + clavulanic acid ${ }^{1}$ & 30 \\
\hline Tetracyclines & Tetracycline ${ }^{2}$ & 30 \\
\hline Rifamycins & Rifampicin ${ }^{1}$ & 5 \\
\hline Carbapenems & Meropenem ${ }^{2}$ & 10 \\
\hline
\end{tabular}


Susceptibility of Staphylococcus spp. and presumptive Enterobacteriaceae (Gram negative) strains to antimicrobial agents was tested using several different antimicrobials discs (Oxoid) as described in Table 1. Antimicrobial agents relevant in terms of the type of microorganisms being tested were chosen and from as many different classes of antimicrobial agents as possible to assess multiresistance.

\section{Antimicrobial susceptibility testing in agar dilution plates}

Susceptibility to antimicrobial agents using agar dilutions was tested according to CLSI and EUCAST standards [7-10]. Mueller-Hinton agar was prepared from a dehydrated base following the manufacturer's instructions. After autoclaving for $15 \mathrm{~min}$ at $121^{\circ} \mathrm{C}$, it was allowed to cool to approximately $60^{\circ} \mathrm{C}$ and the antibiotic solution prepared as described in the CLSI Standards [10] was added and considered with the data provided by the supplier regarding the purity and potency of the antibiotic. After homogenization, the medium was distributed in Petri plates (diameter $90 \mathrm{~mm}$ ) to an approximate height of $4-5 \mathrm{~mm}$. For oxacillin sensitivity tests, dehydrated $\mathrm{MH}$ media was prepared (Oxoid, UK) and after autoclaving, oxacillin was added at concentrations of $0.25 \mu \mathrm{g} / \mathrm{ml}, 0.5 \mu \mathrm{g} / \mathrm{ml}$, $1 \mu \mathrm{g} / \mathrm{ml}, 2 \mu \mathrm{g} / \mathrm{ml}$ and $4 \mu \mathrm{g} / \mathrm{ml}$.

For inoculation, $1 \mu \mathrm{l}$ calibrated loops were used, and the cell suspension with turbidity equivalent to a standard 0.5 MacFarland solution was diluted 1:10 in sterile PS (Merck, Germany) solution to give a concentration of $10^{7} \mathrm{CFU} / \mathrm{ml}$. The application of $1 \mu \mathrm{l}$ of this dilution resulted in a final inoculum of $10^{4} \mathrm{CFU}$ according to CLSI recommendations. Each sample was inoculated at all antibiotic concentrations being tested. Adjusted suspensions were used for final inoculation up to $15 \mathrm{~min}$ after preparation. Inoculated plates remained at room temperature until the inoculum was absorbed into the medium for no longer than $30 \mathrm{~min}$. The plates were then inverted and incubated (Sanyo Incubator, Japan) at $37^{\circ} \mathrm{C}$ for a period of $18 \pm 4 \mathrm{~h}$. Plates were placed on a dark, non-reflective surface to determine endpoints. Minimum Inhibitory Concentration (MIC) was recorded as the lowest concentration of antimicrobial agent that completely inhibits growth, discarding any single colony or slight turbidity caused by the inoculum.

\section{DNA isolation, purification and PCR amplification}

The Staphylococcus spp. strains tested, preserved at $-80^{\circ} \mathrm{C}$ in BHI with $15 \%(\mathrm{v} / \mathrm{v})$ glycerol, were regenerated in $\mathrm{BHI}$ medium at $37^{\circ} \mathrm{C}$ during the night. After regeneration of the cultures, DNA extraction was performed using the Wizard ${ }^{\circledR}$ Genomic DNA Purification kit (Promega, USA). Extraction was carried out according to the manufacturer's instructions with some modifications. Cells were pretreated with $70 \%$ ethanol (Fisher Chemical, UK) according to the procedure described by Kalia, A. and colleagues [11]. Cells were further incubated at $37^{\circ} \mathrm{C}$ for $60 \mathrm{~min}$ after addition of $100 \mu \mathrm{l} 40 \mathrm{mg} /$ $\mathrm{ml}$ lysozyme (Sigma, USA) to facilitate lysis. Isolated DNA was analyzed by electrophoresis and kept at $-20^{\circ} \mathrm{C}$ until used.

Each of the PCR reactions for the detection of mecA and $m e c C$ was a mix $(13 \mu \mathrm{l})$ containing $1.5 \mu \mathrm{l}$ of each $10 \mu \mathrm{M}$ primer (STAB VIDA, Portugal), $6.5 \mu \mathrm{l}$ of SsoFast EvaGreen ${ }^{\circledR}$ Supermix dNTP (Bio-Rad, USA) and $3 \mu$ of DNA from each strain. Specific primers were used for each target gene. Namely mecA1 and mecA2 for gene $m e c A$ [12] . DNA amplification reactions were performed on RT-PCR equipment (Bio-Rad CFX96 ${ }^{\mathrm{TM}}$ Real-time System) under the following conditions: initial denaturation at $95^{\circ} \mathrm{C}$ for $5 \mathrm{~min}$, followed by denaturation over 30 cycles of $15 \mathrm{~s}$ at $95^{\circ} \mathrm{C}, 50 \mathrm{~s}$ at $55^{\circ} \mathrm{C}$ (annealing). After ligation of the primers, an extension occurred at $72^{\circ} \mathrm{C}$ for $30 \mathrm{~s}$. One final step of extension occurred at $72^{\circ} \mathrm{C}$ for $10 \mathrm{~min}$. The primers used for the detection of genes $m e c C$ were mecC $\mathrm{F}$ and mecC $\mathrm{R}$ [13].

The amplification reaction took place over 30 cycles under the following conditions: an initial denaturation at $95^{\circ} \mathrm{C}$ for $5 \mathrm{~min}$, followed by 30 cycles of $15 \mathrm{~s}$ at $95^{\circ} \mathrm{C}$ (denaturation), $60 \mathrm{~s}$ at $59^{\circ} \mathrm{C}$ and $60 \mathrm{~s}$ at $72^{\circ} \mathrm{C}$. One final extension step at $72^{\circ} \mathrm{C}$ for $10 \mathrm{~min}$ was performed. V3F and V3R primers [14] were used as internal amplification control.

After amplification, $5 \mu \mathrm{l}$ of each PCR product were mixed with $2 \mu$ of $6 \mathrm{x}$ concentrated sample buffer: $10 \mathrm{mM}$ Tris (Merck), 500 mM EDTA (Sigma), glycerol (Scharlau, Spain), 0.03\% bromophenol blue (Sigma) and xylene cyanol FF 0.05\% (Sigma).

PCR products were analyzed on $2 \%$ agarose gel (Sigma) in 0.5x TBE buffer (composed of $10 \mathrm{mM}$ Tris, boric acid (Sigma), $500 \mathrm{mM}$ EDTA and distilled water) with $0.5 \mu \mathrm{l} / \mathrm{ml}$ of ethidium bromide (Sigma). As a molecular 
weight standard, DNA ladder (5 $\mu$ l) (Cleaver Scientific, UK) was used on the same agarose gel. Electrophoresis was performed on horizontal electrophoresis equipment (Horizon ${ }^{\circledR} 58$, Life Technologies, USA) for $2 \mathrm{~h}$ at constant $50 \mathrm{~V}$. Subsequently the gel was visualized by UV illumination (Uvitec, UK) in which the migration of the DNA Ladder bands was compared with the migration of the PCR products from the samples and the respective controls.

\section{Results}

\section{Staphylococcus spp. strains antibiotic susceptibility}

Susceptibility of Staphylococcus spp. isolates can be observed in the Table 2 . Of the 49 strains isolated from the air of waste sorting facilities [5], forty-eight strains were coagulase-negative staphylococci (CoNS). A low prevalence of resistance to gentamicin and ciprofloxacin (4\% and $2 \%$, respectively) was observed and $13(26.5 \%)$ isolates, including the coagulase positive strain, demonstrated sensitivity to all antibiotics tested. A significant level of resistance to $\beta$-lactam antibiotics was observed, as 32 isolates were resistant to at least one $\beta$-lactam antibiotic $(65.3 \%), 25$ were resistant to only $\beta$-lactam antibiotics (51\%) and 8 were resistant to $\beta$-lactams and other antimicrobial classes (16.3\%). About $4 \%$ of all rifampicin resistant strains were also resistant to erythromycin. About $10 \%$ of all the erythromycin resistant isolates $(20.8 \%)$ were also oxacillin resistant, followed by $8 \%$ to ampicillin, $4 \%$ to rifampicin and lastly to ciprofloxacin and gentamicin (2\%). Of the studied isolates $24 \%$

Table 2. Antimicrobial susceptibility of the Staphylococcus spp. isolates.

\begin{tabular}{llc}
\hline \multicolumn{1}{c}{ Class } & Antimicrobial agent & $\begin{array}{r}\% \text { of resistant } \\
\text { CoNS isolates }\end{array}$ \\
\hline$\beta$-lactams & Ampicillin & $22.9 \%$ \\
& Amoxicillin + clavulanic acid & $2.1 \%$ \\
Glicopeptides & Oxacillin & $52.1 \%$ \\
Fluoroquinolones & Cancomycin & $2.1 \%$ \\
Macrolides & Erythromycin & $2.1 \%$ \\
Aminoglycosides & Gentamicin & $20.8 \%$ \\
& Amikacin & $4.2 \%$ \\
Rifamycins & Rifampicin & $2.1 \%$ \\
\hline
\end{tabular}

displayed multi-resistency, of which $18 \%$ are resistant to 2 antibiotics and $6 \%$ to 3 or more antibiotics.

Using the method of agar dilutions, twenty five strains (51\%) demonstrated resistance to oxacillin (methicillin resistant), with MICs ranging from $0.5 \mathrm{mg} / \mathrm{l}$ to $4 \mathrm{mg} / \mathrm{l}$, while 12 had a MIC greater than $2 \mathrm{mg} / \mathrm{l}$. The PCR amplicon of $564 \mathrm{bp}$ size corresponding to the amplification of the $m e c A$ gene, was only detected in $8 \%$ of the resistant strains to oxacillin and the mecC gene could not be detected in any strain.

\section{Meropenem resistant Gram negative strains susceptibility to antimicrobial agents}

The screening carried out in the presence of meropenem in mixed cultures preserved at $-80^{\circ} \mathrm{C}$, allowed to obtain a total of 37 Gram negative isolates from all the air samples analysed. The susceptibility of these strains to different antimicrobial agents was studied and, as can be seen in Table 3, the highest incidence of resistance is to $\beta$-lactam antibiotics, cephalothin and cefoxitin (cephalosporins), penicillin, ampicillin and amoxicillin-clavulanic acid (penicillins), all above $45 \%$. No inhibition halo was observed in $35 \%$ of the isolates when tested with

Table 3. Antimicrobial susceptibility of the Gram-negative isolates.

\begin{tabular}{llc}
\hline \multicolumn{1}{c}{ Class } & \multicolumn{1}{c}{ Antimicrobial agent } & $\begin{array}{c}\text { Resistant } \\
\text { CoNS isolates }\end{array}$ \\
\hline Penicillins & Ampicillin & $62 \%$ \\
& Amoxicillin + clavulanic acid & $46 \%$ \\
Glicopeptides & Penicillin & $68 \%$ \\
& Vancomcin* & $8 \%$ \\
Fluoroquinolones & Teicoplanin* & $35 \%$ \\
& Ciprofloxacin & $8 \%$ \\
Aminoglycosides & Nalidixic acid & $24 \%$ \\
& Gentamicin & $3 \%$ \\
Cefalosporinas & Amikacin & $8 \%$ \\
& Neomycin* & $14 \%$ \\
Carbapenems & Cefalotin & $70 \%$ \\
& Cefoxitin & $59 \%$ \\
Macrolides & Tetracycline* & $51 \%$ \\
Rifamycins & Erythromycin* & $3 \%$ \\
\hline
\end{tabular}

Note: *Considered as resistant only strains which did not present any halo. 
teicoplanin, $14 \%$ with neomycin, $8 \%$ with vancomycin, and $3 \%$ with rifampicin.

Due to the instability of the meropenem after preparation (in solution and in plate), the susceptibility of all strains was confirmed by diffusion in agar with meropenem discs, in order to avoid the occurrence of false positives. Only $51 \%$ of the strains isolated from the screening were confirmed positive for resistance to meropenem. Thus, considering all the initial presumptive Enterobacteriaceae isolates tested, $12 \%$ of them were resistant to meropenem. Of the $62 \%$ ampicillin-resistant strains, $59 \%$ are also resistant to cefoxitin and cephalotin, followed by $62 \%$ to penicillin, $54 \%$ to amoxicillin clavulanic acid, $49 \%$ to meropenem, $3 \%$ to gentamycin and no strain displayed resistance to ciprofloxacin, amikacin and tetracycline. Analyzing the strains resistant to amoxicillin - clavulanic acid we found that $59 \%$ present simultaneous resistance to cefoxitin and cephalotin, $57 \%$ to penicillin, $54 \%$ to ampicillin, $49 \%$ to meropenem and $3 \%$ to gentamycin. Strains resistant to cephalothin or meropenem show resistance simultaneously to all antibiotics tested except for amikacin.

In summary, only $5 \%$ of the isolates presented susceptibility to all of the tested antimicrobial agents and 95\% of the isolates showed resistance to at least 1 antibiotic, with $16 \%$ showing resistance to 2 antibiotics, followed by $11 \%$ to 3 antibiotics, $3 \%$ to 4 antibiotics, $19 \%$ resistant to 5 antibiotics, $43 \%$ resistant to 6 antibiotics and $3 \%$ resistant to more than 6 antibiotics.

\section{Discussion}

Despite $51 \%$ of the Staphylococcus spp. isolates demonstrated resistance to oxacillin, resistance to other $\beta$-lactamic antibiotics was found to be significantly lower than that reported in other studies [15-17]. Of all the samples tested, only three Staphylococcus spp. strains showed resistance to three antibiotics. One of these strains showed resistance at least to three antimicrobial classes, considered, therefore, to be multidrug resistant, according to Magiorakos and colleagues classification $[15,18]$. The vancomycin resistant strain is a coagulase negative Staphylococcus spp., but nonetheless a potential reservoir of drug resistance, and waste sorting facilities workers may acquire this potential opportunistic resistant microorganism in their work environment.
Once acquired by the working community it can be spread to the wider community and consequently become a public health problem.

Rapid and accurate detection of methicillin resistance in Staphylococcus spp. is important for treating serious infections. Methicillin resistance is mediated by the protein PBP 2a (penicillin-binding protein), encoded by the $m e c A$ gene, which is an integral part of a mobile genetic element called SCCmec, Staphylococcal cassette chromosome mec [19], and the presence of the mecA gene correlates with oxacillin resistance also in Staphylococcus coagulase negative (CoNS) strains [20]. This gene is often heterogeneously expressed, so conventional sensitivity testing methods may fail to detect methicillin resistance. Current detection of the mecA gene by polymerase chain reaction (PCR) is considered to be the main test for classifying strains as methicillin resistant although there is currently at least one homologue ( $\mathrm{mecC}$ ) gene that confers methicillin resistance in Staphylococcus spp. [21]. We have found the mecA gene in only a small fraction of the oxacillin resistant isolates, but in 2012, in a study of CoNS mutiresistance, the presence of the mecA gene was also found in only $67.8 \%$ of the oxacillin resistant strains [15]. In a study by Olayinka and colleagues (as cited in [22]), the phenomenon found in some phenotypically $S$. aureus MRSA isolates was not a classical resistance mediated by the presence of the corresponding genetic element, but probably caused by an overproduction of $\beta$-lactamase.

Since multiresistance in Enterobacteriaceae has been described in 1990, it that has been emerging in the community [23]. In fact, $95 \%$ of the strains isolated are resistant to more than one antimicrobial agent and $43 \%$ displayed resistance to 6 of the tested antibiotics. The high incidence of resistance to meropenem can be worrying, since carbapenems are considered as the preferred antibacterial agents in the treatment of ESBL-producing Enterobacteriaceae [23, 24]. Considering that $60 \%$ of the Gram negative isolates presented resistance to at least 3 classes of antibiotics these strains are therefore classified as multidrug-resistant (MDR) according to the criteria proposed by Magiorakos and collaborators [18]. Regarding antibiotics used in the groups evaluated, 54\% demonstrated resistance to penicillins, $8 \%$ demonstrated resistance to fluoroquinolones and glycopeptides and $68 \%$ demonstrated resistance to cephalosporins. Regard- 
ing aminoglycosides, resistance to antibiotics from the same group was not found. These data confirm that the highest incidence of resistance consistent with is to cephalosporins and penicillins, as also found in works previously published [23-25]. It is known that carbapenemasesproducing Enterobacteriaceae are resistant to $\beta$-lactams, including cephalosporins, penicillins and monobactams [24].

Douwes and colleagues [26], and Brooks and colleagues [27] reported that a wide variety of health problems, including infectious diseases, acute toxic effects, allergies, cancer, respiratory symptoms and changes in lung function in workers exposed to bioaerosols in the occupational environment. The potential danger of bioaerosols depends on the pathogenicity of microorganisms, environmental factors, as well as the pools of bacteria genes, including antibiotic resistance genes. According to Paterson and colleagues [24], Gram negative bacteria from the Enterobacteriaceae family are major causes of urinary tract infections (UTI), bloodstream infections, pneumonia associated with healthcare, and various intra-abdominal infections.

Carbapenemase-producing strains are characterized by their resistance to virtually all $\beta$-lactam antibiotics and to many other antibiotic classes [25]. Its rapid emergence poses a considerable threat to public health due to the capacity to spread easily between humans, contaminated food, and water.

\section{Conclusion}

The present study, provide of evidence that waste sorting facilities can be a source for carbapenem resistant Gram negative bacteria and Staphylococcus spp. strains. Their circulation between the environment and workers presents a risk not usually taken into account when risk assessment is performed.

The fact that waste sorting facilities and landfill workers are subjected to the exposure to high levels of biological agents naturally makes these workers more frequent targets of potential exposure to multidrug-resistant pathogenic or opportunistic organisms. The present study can contribute to a better understanding of this reality, and raise awareness among the various operators in the sector of a risk that is not usually considered.

\section{Acknowledgments}

Part of the work here presented had the financial support of the Portuguese Working Conditions Authority (Autoridade para as Condições de Trabalho-ACT), project 51APJ-08.

\section{Conflict of Interest}

The authors have no financial conflicts of interest to declare.

\section{References}

1. Anderson M, Clift C, Schulze K, Sagan A, Nahrgang S, Alt Ouakrim D, et al. 2019. Averting the AMR Crisis: What are the Avenues for Policy Action for Countries in Europe. In POLICY BRIEF 32, European Observatory on Health Systems and Policies, WHO.

2. World Health Organization. 2020. Antibiotic Resistance. Available from https://www.who.int/news-room/fact-sheets/detail/antibiotic-resistance. Accessed Jan. 30, 2020.

3. Berendonk TU, Manaia CM, Merlin C, Fatta-Kassinos D, Cytryn E, Walsh F, et al. 2015. Tackling antibiotic resistance: the environmental framework. Nat. Rev. Microbiol. 13: 310-317.

4. Brun E. 2007. Expert forecast on emerging biological risks related to occupational safety and health. Luxembourg: EUR-OP.

5. Pinto MJdV, Veiga JM, Fernandes $P$, Ramos C, Gonçalves $S$, Velho MMLV, et al. 2015. Airborne microorganisms associated with packaging glass sorting facilities. J. Toxicol. Environ. Health Part $A$. 78: 685-696.

6. Matuschek E, Brown DF, Kahlmeter G. 2014. Development of the EUCAST disk diffusion antimicrobial susceptibility testing method and its implementation in routine microbiology laboratories. Clin. Microbiol. Infect. 20: O255-266.

7. Leclercq R, Cantón R, Brown DFJ, Giske CG, Heisig P, MacGowan AP, et al. 2013. EUCAST expert rules in antimicrobial susceptibility testing. Clin. Microbiol. Infect. 19: 141-160.

8. CLSI. 2012. Performance Standards for Antimicrobial Disk Susceptibility Tests; Approved Standard-11th, Ed. CLSI document M02A11.

9. The European Comittee on Antimicrobial Susceptibility Testing. 2014. Breakpoint tables for interpretation of MICs and zone diameters. Version 4.0, 2014. http://www.eucast.org.

10. CLSI. 2012. Methods for Dilution Antimicrobial Susceptibility Tests f or Bacteria That Grow Aerobically; Approved St andard9th, Ed. CLSI document M07-A9.

11. Kalia A, Rattan A, Chopra P, Kalia A, Rattan A, Chopra P. 1999. A method for extraction of high-quality and high-quantity genomic DNA generally applicable to pathogenic bacteria. Anal. Biochem. 275: 1-5.

12. Murakami K, Minamide W, Wada K, Nakamura E, Teraoka $H$, Watanabe S. 1991. Identification of methicillin-resistant strains of staphylococci by polymerase chain reaction. J. Clin. Microbiol. 29: 2240-2244. 
13. DTU Food NFI, European Union Reference Laboratory-Antibiotic Resistance. 2012. Protocol for PCR Amplification of mecA, mecC (mecALGA251), spa and pvl. https://www.eurl-ar.eu/CustomerData/Files/Folders/21-protocols/279_pcr-spa-pvl-meca-meccsept12. pdf. Accessed Nov. 16, 2017.

14. Muyzer G, Dewaal EC, Uitterlinden AG. 1993. Profiling of complex microbial-populations by denaturing gradient gel-electrophoresis analysis of polymerase chain reaction-amplified genes-coding for 16s ribosomal-RNA. Appl. Environ. Microbiol. 59: 695-700.

15. Bhargava K, Zhang Y. 2012. Multidrug-resistant coagulase-negative Staphylococci in food animals. J. Appl. Microbiol. 113: 1027-1036.

16. Fontes CO, Silva VL, de Paiva MRB, de Paiva B, Garcia RA, Resende $\mathrm{JA}$, et al. 2013. Prevalence, antimicrobial resistance, and virulence characteristics of mecA-encoding coagulase-negative Staphylococci isolated from soft cheese in Brazil. J. Food Sci. 78: M594M599.

17. Nascimento TC, Januzzi WD, Leonel $M$, da Silva VL, Diniz CG. 2009. Occurrence of clinically relevant bacteria in health service waste in a Brazilian sanitary landfill and antimicrobial susceptibility profile. Rev. Soc. Bras. Med. Trop. 42: 415-419.

18. Magiorakos AP, Srinivasan A, Carey RB, Carmeli Y, Falagas ME, Giske CG, et al. 2012. Multidrug-resistant, extensively drug-resistant and pandrug-resistant bacteria: an international expert proposal for interim standard definitions for acquired resistance. Clin. Microbiol. Infect. 18: 268-281.

19. Laurent F, Chardon H, Haenni M, Bes M, Reverdy M-E, Madec J-Y, et al. 2012. MRSA harboring mecA variant gene mecC, France. Emerg. Infect. Dis. 18: 1465-1467.
20. Perazzi B, Fermepin MR, Malimovka A, García SD, Orgambide M, Vay CA, et al. 2006. Accuracy of cefoxitin disk testing for characterization of oxacillin resistance mediated by penicillin-binding protein 2a in coagulase-negative Staphylococci. J. Clin. Microbiol. 44: 3634-3639.

21. Ghoshal U, Prasad KN, Singh M, Tiwari DP, Ayyagari A. 2004. A comparative evaluation of phenotypic and molecular methods for the detection of oxacillin resistance in coagulase-negative staphylococci. J. Infect. Chemother. 10: 86-89.

22. Elhassan MM, Ozbak HA, Hemeg HA, Elmekki MA, Ahmed LM. 2015. Absence of the mecA Gene in methicillin resistant Staphylococcus aureus isolated from different clinical specimens in Shendi City, Sudan. BioMed. Res. Int. 2015: 895860-895860.

23. Pitout JD, Laupland KB. 2008. Extended-spectrum beta-lactamaseproducing Enterobacteriaceae: an emerging public-health concern. Lancet Infect. Dis. 8: 159-166.

24. Paterson DL. 2006. Resistance in gram-negative bacteria: enterobacteriaceae. Am. J. Med. 119: S20-S28.

25. Cohen Stuart J, Leverstein-Van Hall MA. 2010. Guideline for phenotypic screening and confirmation of carbapenemases in Enterobacteriaceae. Int. J. Antimicrob. Agents 36: 205-210.

26. Douwes J, Thorne P, Pearce N, Heederik D. 2003. Bioaerosol health effects and exposure assessment: progress and prospects. Ann. Occup. Hyg. 47: 187-200.

27. Brooks JP, Maxwell SL, Rensing C, Gerba CP, Pepper IL. 2007. Occurrence of antibiotic-resistant bacteria and endotoxin associated with the land application of biosolids. Can. J. Microbiol. 53: 616-622. 